\title{
Indian experience of AUS/FLUS diagnosis: is it different from rest of Asia and the West? -A systematic review and meta-analysis
}

\author{
Prerna Guleria $^{1}$, Kalaivani Mani ${ }^{2}$, Shipra Agarwal ${ }^{3}$ \\ ${ }^{1}$ Department of Laboratory Sciences and Molecular Medicine, Army Hospital Research and Referral, New Delhi, India; ${ }^{2}$ Department of Biostatistics, \\ ${ }^{3}$ Department of Pathology, All India Institute of Medical Sciences, New Delhi, India \\ Contributions: (I) Conception and design: S Agarwal, P Guleria; (II) Administrative support: None; (III) Provision of study materials or patients: \\ None; (IV) Collection and assembly of data: S Agarwal, P Guleria; (V) Data analysis and interpretation: K Mani; (VI) Manuscript writing: All \\ authors; (VII) Final approval of manuscript: All authors. \\ Correspondence to: Dr. Shipra Agarwal, MD. Associate Professor, Department of Pathology, All India Institute of Medical Sciences, New Delhi, India. \\ Email: drshipra0902@gmail.com.
}

Background: Atypia of undetermined significance/follicular lesion of undetermined significance (AUS/ FLUS) is the most heterogeneous subcategory of the Bethesda system for thyroid cytopathology with laid down permissible limits of frequency and risk of malignancy (ROM). Due to differences in thyroid clinical practice worldwide, variations have been found in frequency, resection rates (RR) and ROM. Therefore, this systematic review and meta-analysis of AUS/FLUS across different regions was conducted and comparison of data from India was done with the rest of Asia and the West.

Methods: We searched PubMed and Google search engines from January 2009-Dec 2019 using terms "AUS Thyroid" and "FLUS Thyroid". Meta-analysis was performed using DerSimonian-Laird method and 95\% confidence intervals were calculated using random effects model. Independent samples t-test was used to compare frequency, RR, and ROM of AUS/FLUS between India, rest of Asia and the West.

Results: Out of 15,000 studies on internet, 60 (18 Indian, 12 Asian and 30 Western) were included. Total aspirates were 201,657; 14,279 Indian, 62,448 Asian, 124,930 Western. Pooled estimates were: frequency 7.3\% (6.3-8.3\%), RR 41.9\% (37.4-46.6\%), ROM 33.3\% (26.8-39.9\%). Pooled prevalence of rate did not vary significantly across the three regions. Pooled prevalence of RR was highest in India (52.9\%) and lowest in rest of Asia (26.5\%); of ROM was highest in Asia (45.9\%), lowest in the West $(26.3 \%)(\mathrm{P}<0.01)$. Statistical analysis demonstrated publication bias, limited to Indian and Western studies. Papillary thyroid carcinoma was the most common surgical diagnosis $(87.9 \% ; 1,082 / 1,231)$.

Conclusions: This meta-analysis showed differences in thyroid clinical practice followed in India, rest of Asia and the West. Although pooled prevalence of rate of AUS/FLUS was similar across the three, pooled RR and ROM varied. AUS/FLUS nodules were more frequently resected in Indian and Western studies than in rest of Asia. ROM was higher than recommended values in all three areas, being intermediate for India.

Keywords: Atypia of undetermined significance/follicular lesion of undetermined significance thyroid (AUS/ FLUS thyroid); resection rate (RR); risk of malignancy (ROM); Indian; meta-analysis

Submitted Mar 24, 2020. Accepted for publication May 13, 2020.

doi: 10.21037/gs-20-392

View this article at: http://dx.doi.org/10.21037/gs-20-392

\section{Introduction}

Fine needle aspiration cytology (FNA) forms an important means of detecting thyroid pathologies with a substantial amount of reliability, influencing clinical management.
To provide universal reporting guidelines to all cytopathologists, the Bethesda System for Reporting Thyroid Cytopathology (TBSRTC) was formulated in 2007 (1) and later revised in $2017(2,3)$. This system classifies a 
thyroid FNA into six diagnostic categories namely (I) non-diagnostic, (II) benign, (III) atypia of undetermined significance/follicular lesion of undetermined significance (AUS/FLUS), (IV) follicular neoplasm/suspicious for follicular neoplasm, (V) suspicious for malignancy, and (VI) malignant; each category having an implied risk of malignancy (ROM) and recommended management protocol. The system has been widely adopted across the world for thyroid cytology reporting (4).

The AUS/FLUS category is the most heterogeneous among the six subcategories, defined by a set of nine distinct diagnostic criteria. TBSRTC has laid down guidelines for permissible frequency and ROM of the AUS/FLUS to prevent overuse and for quality control (1). Meta-analysis studies have documented a wide range in the frequency and ROM of AUS/FLUS (5-9). However, most of the data analyzed in these studies is derived from western publications. Also, differences in thyroid clinical practice have been documented between Asia and the West (10-14), but lack detailed meta-analysis work-up.

India, owing to iodine-deficiency, has a high prevalence of endemic goitre. A recent meta-analysis on the status of thyroid cytology in India reported a high ROM in the AUS/ FLUS subcategory (15).

Therefore, the present systematic review and metaanalysis aimed to review the literature on AUS/FLUS across the globe, assessing the category's prevalence, resection rate (RR) and ROM, while comparing the data from India with the rest of Asia and the West. We present the following article in accordance with the Preferred Reporting Items for Systematic Review and Meta-analysis (PRISMA) reporting checklist (available at http://dx.doi.org/10.21037/gs-20392).

\section{Methods}

\section{Search strategy and study identification}

We searched for relevant articles in PubMed and Google search engines from January 2009 till Dec 2019. We searched using the terms "AUS Thyroid" and "FLUS Thyroid". All studies which were found on the internet were evaluated. Additionally, we carried out a thorough evaluation of the citations within the included publications and reviews. We followed the recommendations of the PRISMA statement (16).

\section{Selection criteria and abstract screening}

After searching electronic databases, search results were imported into Mendeley (Elsevier, Amsterdam, Netherlands). Two reviewers (PG, SAG) independently screened the titles and abstracts for potential articles. Studies fulfilling the following criteria were included: (I) use of TBSRTC 2007 for reporting thyroid cytopathology, with (II) availability of data regarding the total number of thyroid FNAs, the distribution of cases according to TBSRTC 2007 or at least mentioning the total number of AUS cases reported, the number of AUS cases undergoing resection, and number of AUS cases with a malignant diagnosis.

The exclusion criteria were: (I) use of other classification systems or TBSRTC 2017 for reporting, (II) inadequate data provided to calculate the frequency, RR or ROM of the AUS category, e.g., studies based only on cases with available surgical follow-up, (III) studies based on tru-cut biopsy, (IV) those dealing with only pediatric population, (V) those dealing solely with sub-centimetric nodules, (VI) studies using pre-operative ultrasound and molecular tests that can bias the RR and ROM, (VII) case reports, (VIII) reviews, (IX) conference-related proceedings, posters, theses, (X) use of a language other than English, and (XI) publications where only abstract was available. In case of more than one study being published from the same institute with overlapping time period, and potential of overlapping data, only the study with the higher number of cases was included. Diagnosis of repeat aspirations, in case performed, was not considered. Discrepancies, if any, were resolved by discussion and consensus.

\section{Full-text screening and data extraction}

All the potential articles were screened by the two reviewers. The studies were segregated into three groups depending upon the location of the institute where the study was carried out, as those from India, (rest of) Asia or from the West. The data as defined above was recorded in an excel sheet with pre-defined headings. The various headings used in the excel were as follows: name of the researcher, year in which the study was published, institution, country, the total number of thyroid nodules aspirated, number of cases designated AUS, number of AUS aspirates that were resected and number of malignant cases at resection. As many studies included were published prior to 2016, 
to maintain uniformity Non-Invasive Follicular Thyroid neoplasm with Papillary-like nuclear features (NIFTP), wherever specified, was deemed malignant. Histopathology details of malignancies were also noted.

\section{Data analysis}

The meta-analysis was performed using the DerSimonianLaird method and their $95 \%$ confidence intervals (CI) were calculated using the random effects model. The frequency, $\mathrm{RR}$ and ROM of AUS were determined by calculating the proportion of AUS cases to the total number of aspirates, nodules resected to the total number of AUS aspirates and malignant nodules on resection to the total number of resected nodules (ROM-resection), respectively and then multiplied by 100 . The overall ROM (ROM-overall) was calculated taking the total number of AUS aspirates as the denominator. Forest plots were generated displaying prevalence with corresponding $95 \%$ CI. The variation in the magnitude of the effect was examined and heterogeneity was quantified using I-squared statistic. Funnel plots were used to detect potential reporting bias and small/large study effects and the Egger's regression method was used to assess asymmetry. Sensitivity analysis was carried out to investigate the effect of studies that had very large prevalence. Oneway ANOVA test was used to compare frequencies, RR, and ROM among Indian, Asian and Western practices. A P value of $<0.05$ was considered statistically significant.

\section{Results}

We found a total of 15,000 studies on the internet when we used the selected phrases for search in PubMed and Google search engines for the defined period. Of these, 60 studies [18 from India (13,17-33), 12 from Asia (13,34-44), and 30 from the West $(8,45-73)$ ] (Table 1) fulfilled all the inclusion and exclusion criteria. The study by Bychkov et al. (13), is an Asian multi-institutional study, from which the data from India was extracted, and analyzed with the rest of the studies from India. The studies by Faquin (53) and Zhou (73) were multi-institutional and both had data from the University of Pennsylvania. Hence, due to the possibility of there being an overlap, the patient data of the University of Pennsylvania was excluded from the paper by Zhou et al. (73).

There were a total of 201,657 thyroid FNAs out of which 14,279 were from Indian studies, 62,448 from the other Asian studies, and 124,930 were from the studies of the Western region.
Considering all studies from all three zones, pooled estimate of frequency was $7.3 \%(6.3-8.3 \%)$, of RR was 41.9\% (37.4-46.6\%), of ROM-resection was 33.3\% (26.8$39.9 \%)$ and of ROM-overall was $11.1 \%(9.3-12.9 \%)$.

Considering the three areas separately (Figures 1-3), the pooled frequency of AUS ranged from $5.8 \%$ (India) to $8.7 \%$ (Asia) (Table 2, Figures $1 A, 2 A, 3 A$ ) and did not vary significantly across the three regions (Table 3 ). The pooled RR was highest in India (52.9\%) and lowest in the rest of Asia $(26.5 \%$ ) (Figures 1B,2B,3B); pooled prevalence for ROM-resection was highest in Asia (45.9\%) but lowest in the West (26.3\%) (Table 2; Figures 1C,2C,3C) and was significantly different between the two regions $(\mathrm{P}<0.01)$ (Table 3). ROM-overall was similar across the three regions, ranging from $10.1 \%$ to $14.4 \%$ (Figures 1D,2D,3D).

Even after sensitivity analysis, heterogeneity across the studies persisted. The pooled estimate of RR in India decreased from $52.95 \%$ (38.56-67.35\%) to $46.69 \%$ (32.87$60.51 \%)$ and the pooled estimate of ROM-resection in Asia decreased from $45.86(32.15-59.56 \%)$ to $35.00 \%$ (22.05$47.96 \%)$.

Funnel plots demonstrated presence of publication bias mostly in Indian and Western studies (Figure 4).

Considering results of only those studies in which histopathological outcome of all malignancies was specified, papillary thyroid carcinoma (PTC) was the most common surgical diagnosis $(87.9 \% ; 1,082 / 1,231)$, but PTC subtypes were not detailed in all reports. Of the studies with details available, borderline tumors and low-grade cancers (NIFTP, follicular variant of PTC and tumors of uncertain malignant potential) constituted $41.7 \%$ (40/96) of the available diagnoses from India, 24.4\% (82/336) from Asia and $51.8 \%$ (246/475) from the West. The rest of the malignant diagnoses included other PTC variants (including papillary microcarcinoma), follicular carcinoma, Hurthle cell carcinoma, poorly differentiated thyroid carcinoma, anaplastic thyroid carcinoma, medullary thyroid carcinoma, lymphoma and metastasis. There was no case of hyalinizing trabecular adenoma.

\section{Discussion}

Thyroid cancer forms around 3\% of all malignancies and is the most common endocrine malignancy (74). The incidence varies across the globe and even across different regions of a country. In India, the incidence is highest in the southern and north-eastern regions $(75,76)$.

FNAC is the primary screening test performed for 
Table 1 Comprehensive data of the studies included in the meta-analysis

\begin{tabular}{|c|c|c|c|c|c|}
\hline Serial No. & Study & Total FNA & No. of AUS & No. of resections & $\begin{array}{c}\text { No. of malignant } \\
\text { nodules }\end{array}$ \\
\hline \multicolumn{6}{|c|}{ Indian studies } \\
\hline 1. & Arul 2015 (17) & 603 & 60 & 41 & 10 \\
\hline 2. & Badge 2016 (18) & 120 & 11 & 4 & 1 \\
\hline 4. & Bychkov $2018(13)^{\star}$ & 1,339 & 147 & 35 & 12 \\
\hline 5. & Chandra 2017 (20) & 971 & 63 & 35 & 18 \\
\hline 6. & Garg S 2015 (21) & 100 & 4 & 4 & 1 \\
\hline 7. & Garg S 2017 (22) & 1,169 & 76 & 24 & 8 \\
\hline 10. & Mahajan 2017 (25) & 4,562 & 116 & 12 & 6 \\
\hline 11. & Maity 2019 (26) & 282 & 24 & 19 & 5 \\
\hline 12. & Mamatha 2015 (27) & 240 & 8 & 8 & 4 \\
\hline 13. & Mehra 2015 (28) & 225 & 11 & 1 & 1 \\
\hline 14. & Mondal 2013 (29) & 1,020 & 10 & 5 & 1 \\
\hline 15. & Prathima 2016 (30) & 178 & 2 & 2 & 1 \\
\hline 16. & Roy 2019 (31) & 1,018 & 132 & 47 & 37 \\
\hline 20. & Al-Abbadi 2013 (35) & 205 & 15 & 9 & 4 \\
\hline 21. & Al Dawish 2017 (36) & 1,433 & 131 & 42 & 6 \\
\hline 22. & Bychkov $2018(13)^{\star}$ & 10,033 & 619 & 180 & 84 \\
\hline 23. & Kim 2017 (37) & 35,073 & 3,708 & 722 & 514 \\
\hline 24. & Kim 2018 (38) & 5,549 & 882 & 306 & 232 \\
\hline 25. & Lee 2017 (39) & 1,925 & 206 & 50 & 28 \\
\hline 26. & Limlunjakorn 2017 (40) & 2,762 & 108 & 29 & 11 \\
\hline 27. & Liu 2017 (41) & 2,838 & 195 & 21 & 15 \\
\hline 28. & Mufti 2012 (42) & 250 & 2 & 2 & 1 \\
\hline 29. & Naz 2014 (43) & 528 & 67 & 6 & 2 \\
\hline 30. & Satoh 2017 (44) & 1,600 & 171 & 47 & 7 \\
\hline
\end{tabular}

Table 1 (continued) 
Table 1 (continued)

\begin{tabular}{|c|c|c|c|c|c|}
\hline Serial No. & Study & Total FNA & No. of AUS & No. of resections & $\begin{array}{c}\text { No. of malignant } \\
\text { nodules }\end{array}$ \\
\hline \multicolumn{6}{|c|}{ Western studies } \\
\hline 31. & Bernstein 2016 (45) & 2,939 & 233 & 187 & 86 \\
\hline 32. & Bohacek 2012 (46) & 1,000 & 8 & 8 & 1 \\
\hline 34. & Bonzanini 2011 (48) & 2,422 & 242 & 45 & 19 \\
\hline 35. & Brandler 2016 (49) & 11,481 & 976 & 264 & 88 \\
\hline 36. & Can 2016 (50) & 6,290 & 410 & 153 & 70 \\
\hline 37. & Cristo 2016 (51) & 328 & 37 & 16 & 2 \\
\hline 40. & Güney 2017 (54) & 1,440 & 53 & 11 & 1 \\
\hline 41. & Guo 2017 (55) & 236 & 8 & 3 & 1 \\
\hline 42. & Harvey 2013 (56) & 3,432 & 72 & 31 & 5 \\
\hline 43. & Ho 2014 (57) & 8,862 & 709 & 350 & 135 \\
\hline 44. & Horne 2012 (58) & 6,205 & 171 & 58 & 29 \\
\hline 45. & Jo 2010 (59) & 3,080 & 104 & 53 & 9 \\
\hline 46. & Kantola 2015 (60) & 2,159 & 159 & 67 & 29 \\
\hline 51. & Nayar 2009 (64) & 5,194 & 924 & 430 & 26 \\
\hline 52. & Olson 2013 (65) & 3,885 & 575 & 106 & 32 \\
\hline 53. & Paajanen 2018 (66) & 363 & 32 & 7 & 0 \\
\hline 54. & Renshaw 2017 (67) & 12,763 & 961 & 367 & 85 \\
\hline 55. & Tepeoğlu 2014 (68) & 1,021 & 100 & 79 & 10 \\
\hline 56. & Ugurluoglu 2015 (69) & 1,096 & 29 & 7 & 1 \\
\hline 57. & Wu 2014 (70) & 3,346 & 670 & 138 & 25 \\
\hline 58. & Yang 2007 (71) & 4,703 & 152 & 52 & 10 \\
\hline 59. & Yassa 2007 (72) & 3,589 & 144 & 84 & 20 \\
\hline 60. & Zhou 2018 (73) & 12,580 & 786 & 450 & 80 \\
\hline
\end{tabular}

*The study by Bychkov et al. (13) had cases from India and other Asian countries. Data from India and the other countries was segregated and evaluated. FNA, fine needle aspiration; AUS, atypia of undetermined significance. 


$$
\text { 高 }
$$

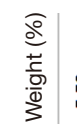

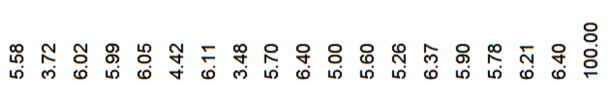

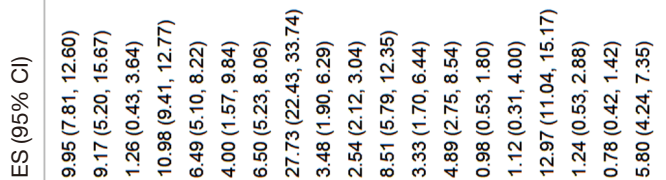

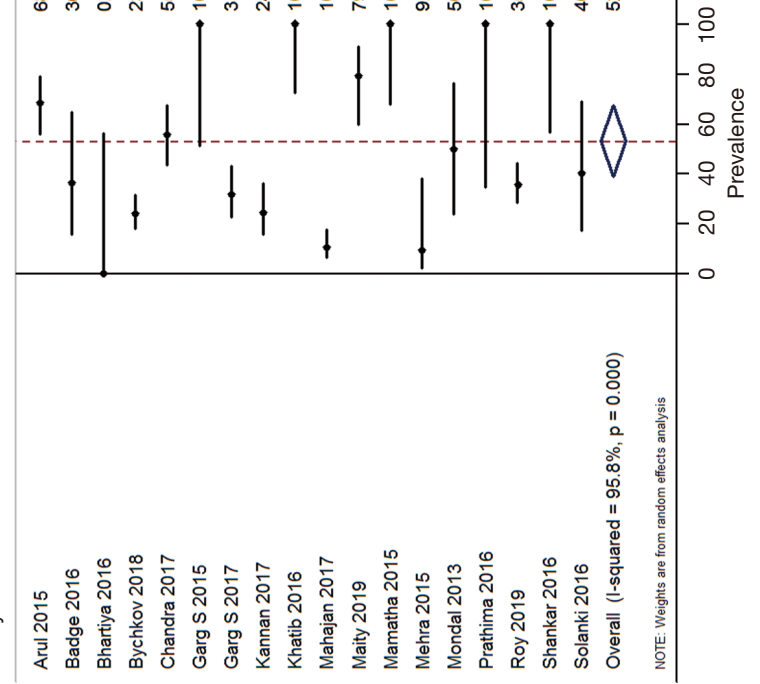

$\infty$
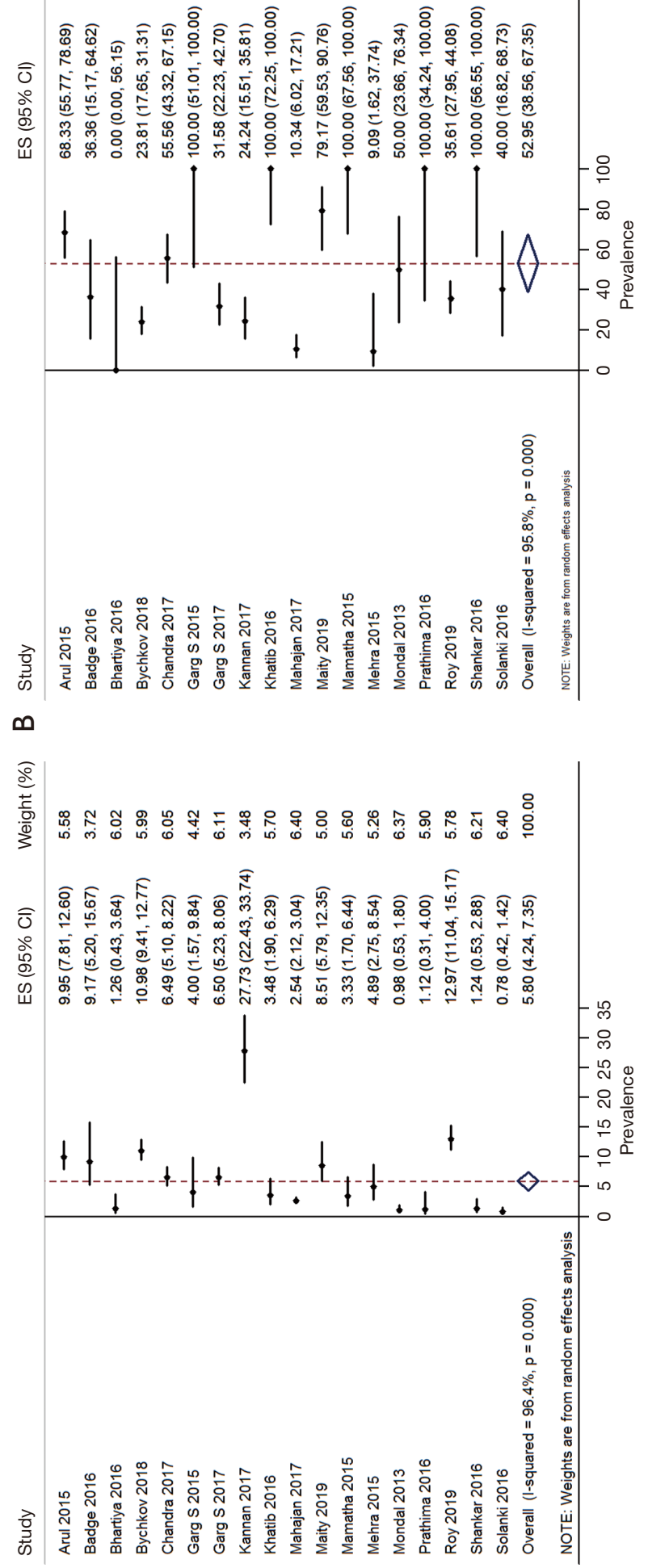

$\varangle$ $\frac{\substack{0 \\ \frac{0}{2}}}{\frac{0}{2}}$

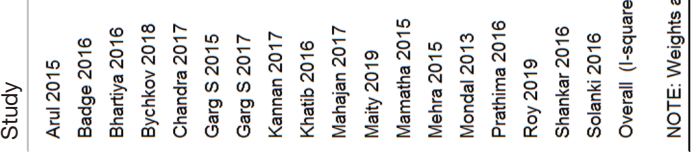

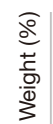

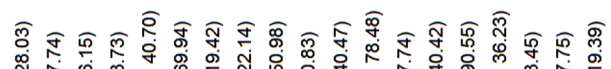

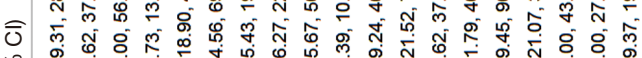

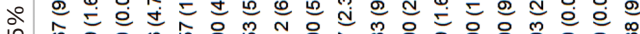

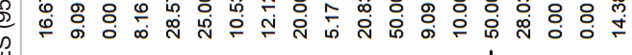

山
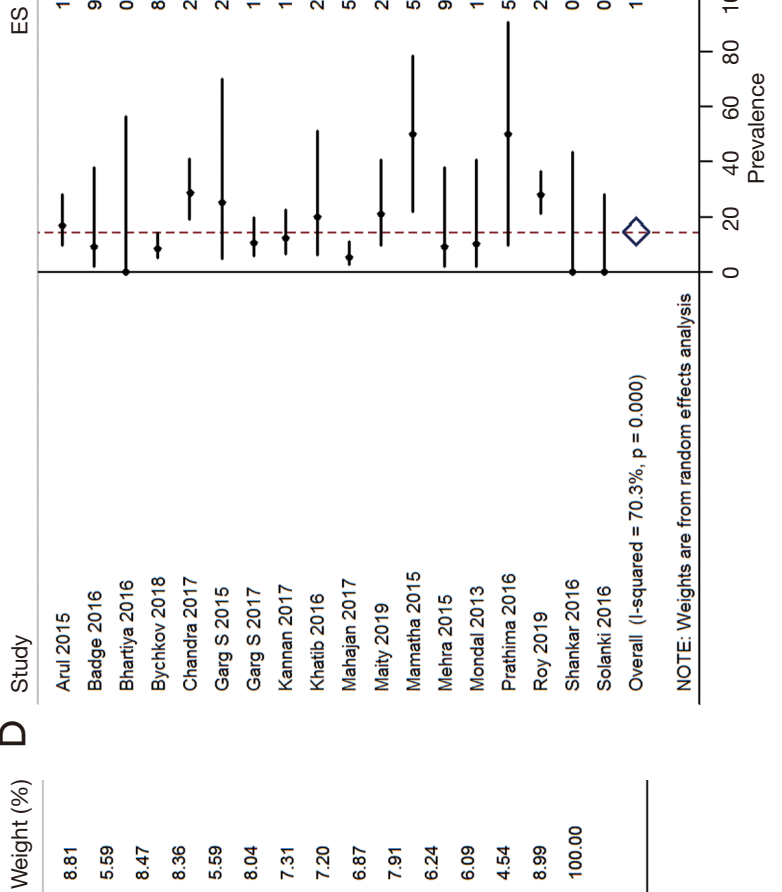

บे

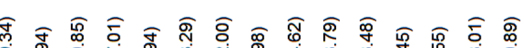

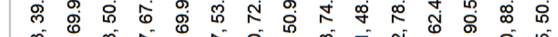

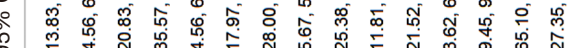

等

山

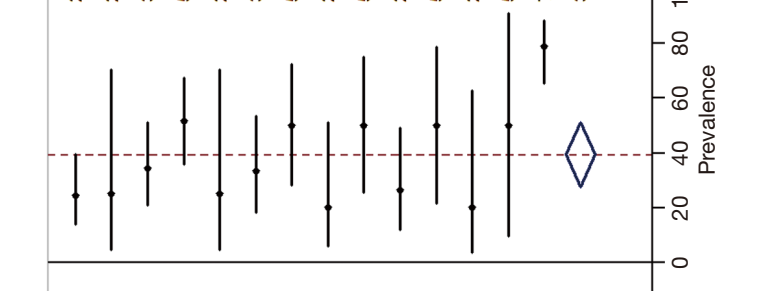

>

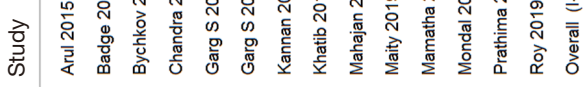



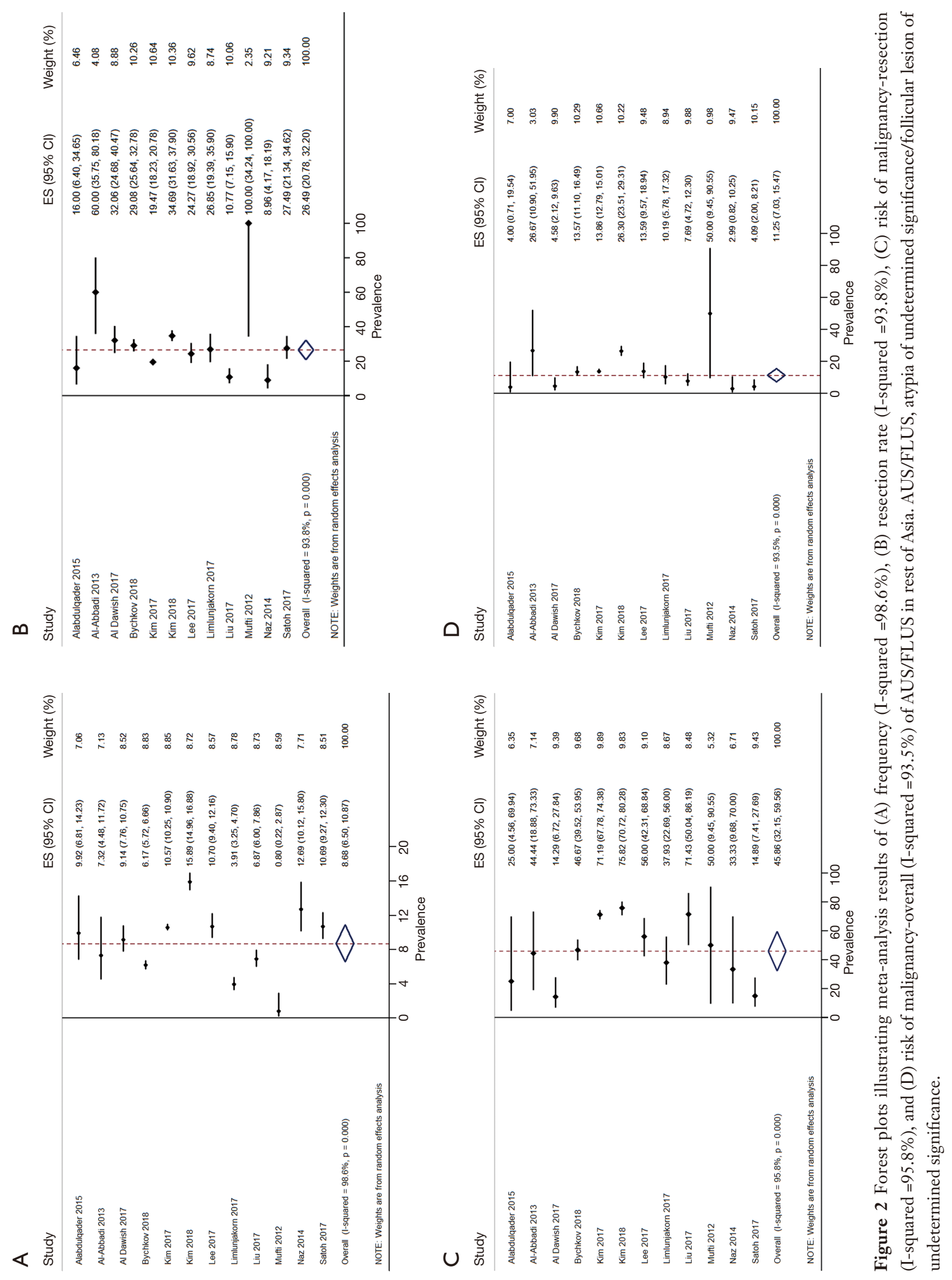
A

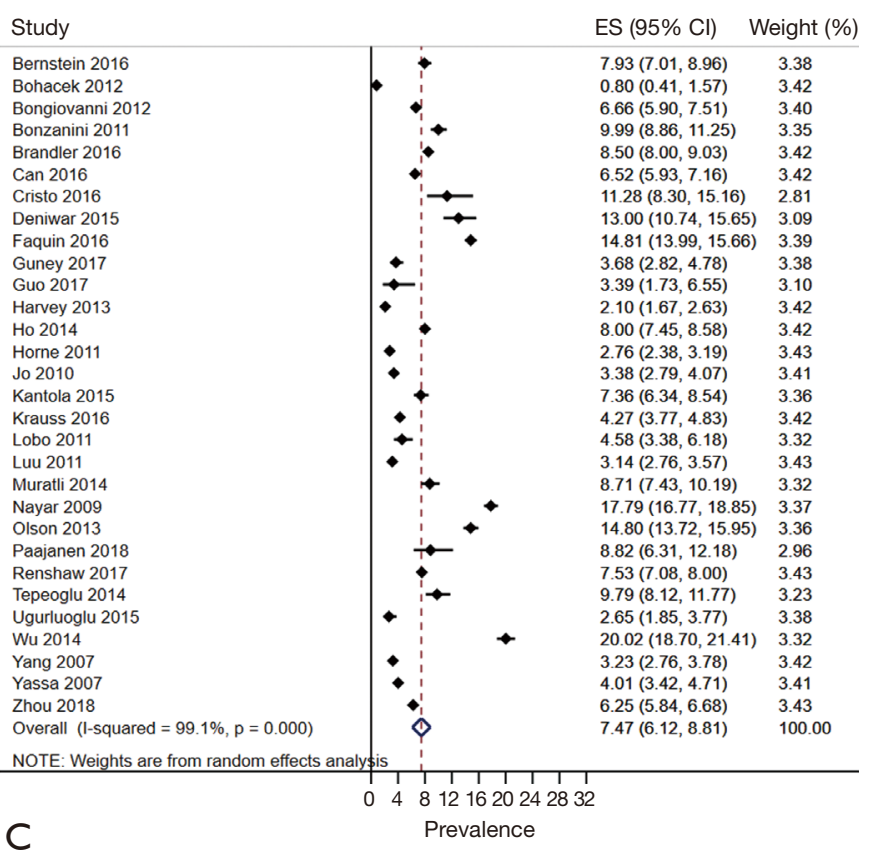

Study

\begin{tabular}{|c|c|c|c|}
\hline Bernstein 2016 & $\begin{array}{r:}-\infty \\
\end{array}$ & $45.99(39.00,53.14)$ & 3.91 \\
\hline & & $12.50(2.24,47.09)$ & 2.38 \\
\hline Bongiovanni 2012 & $\leftarrow$ & $14.39(9.41,21.39)$ & 3.99 \\
\hline Bonzanini 2011 & $\rightarrow$ & $42.22(28.97,56.70)$ & 3.25 \\
\hline Brandler 2016 & & $33.33(27.92,39.22)$ & 4.01 \\
\hline Can 2016 & & $45.75(38.06,53.65)$ & 3.85 \\
\hline Cristo 2016 & $\rightarrow$ & $12.50(3.50,36.02)$ & 3.00 \\
\hline Deniwar 2015 & : & $33.85(23.53,45.96)$ & 3.53 \\
\hline Faquin 2016 & & $31.23(26.87,35.95)$ & 4.08 \\
\hline Guney 2017 & $\rightarrow$ & $9.09(1.62,37.74)$ & 2.81 \\
\hline Guo 2017 & & $33.33(6.15,79.23)$ & 1.38 \\
\hline Harvey 2013 & $\rightarrow$ & $16.13(7.09,32.63)$ & 3.37 \\
\hline Ho 2014 & & $38.57(33.62,43.77)$ & 4.05 \\
\hline Horne 2011 & & $50.00(37.54,62.46)$ & 3.40 \\
\hline Jo 2010 & & $16.98(9.20,29.23)$ & 3.65 \\
\hline Kantola 2015 & & $43.28(32.10,55.19)$ & 3.50 \\
\hline Krauss 2016 & & $25.45(15.81,38.30)$ & 3.53 \\
\hline Lobo 2011 & & $40.00(16.82,68.73)$ & \\
\hline Luu 2011 & & $25.98(19.14,34.24)$ & 3.87 \\
\hline Muratli 2014 & & $26.32(11.81,48.79)$ & 2.76 \\
\hline Nayar 2009 & $\bullet$ & $6.05(4.16,8.71)$ & 4.18 \\
\hline Olson 2013 & & $30.19(22.27,39.49)$ & 3.78 \\
\hline Renshaw 2017 & 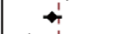 & $23.16(19.14,27.74)$ & 4.09 \\
\hline Tepeoglu 2014 & $\leftarrow 1$ & $12.66(7.02,21.76)$ & 3.89 \\
\hline Ugurluoglu 2015 & & $14.29(2.57,51.31)$ & 2.21 \\
\hline Wu 2014 & $\rightarrow-1$ & $18.12(12.58,25.38)$ & 3.96 \\
\hline Yang 2007 & & $19.23(10.80,31.90)$ & 3.60 \\
\hline Yassa 2007 & & $23.81(15.97,33.94)$ & 3.75 \\
\hline Zhou 2018 & & $17.78(14.52,21.58)$ & 4.13 \\
\hline Overall (I-squared $=93.2 \%, p=0.000$ ) & () & $26.29(21.05,31.54)$ & 100.00 \\
\hline NOTE: Weights are from random effects analysis & & & \\
\hline
\end{tabular}

B

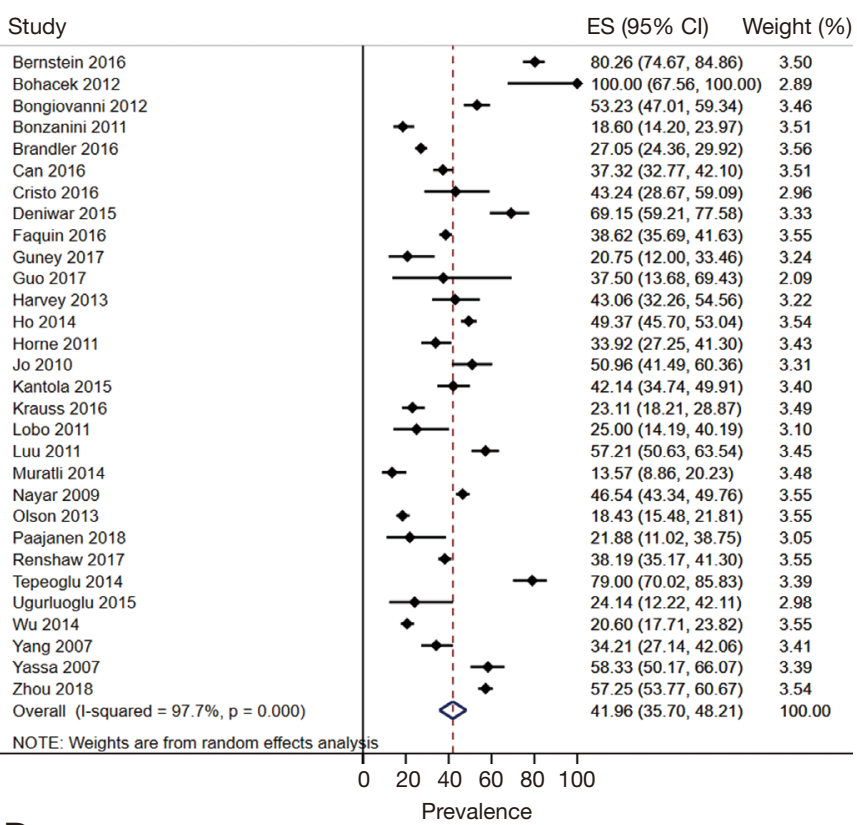

D

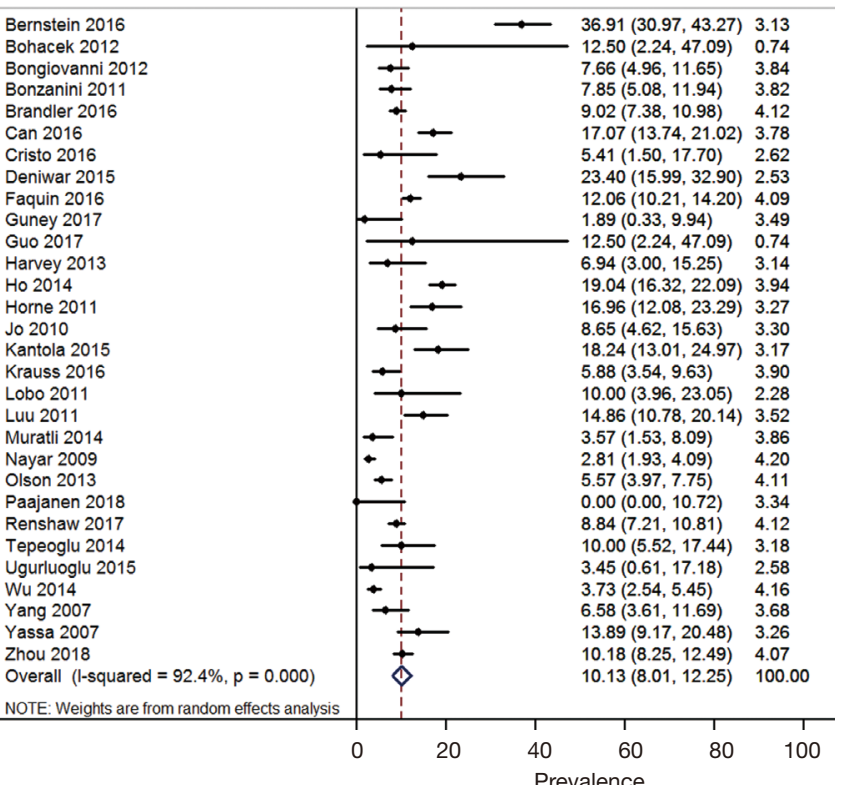

Figure 3 Forest plots illustrating meta-analysis results of (A) frequency (I-squared =99.1\%), (B) resection rate (I-squared =97.7\%), (C) risk of malignancy-resection (I-squared =93.2\%), and (D) risk of malignancy-overall (I-squared =92.4\%) of AUS/FLUS in West. AUS/FLUS, atypia of undetermined significance/follicular lesion of undetermined significance.

all thyroid swellings, aiding in segregating benign from malignant. To maintain uniformity in reporting across the World and facilitate easy interpretation by the clinicians, TBSRTC was formulated in 2007 (1). Of the six cytology categories described under TBSRTC, category III (AUS/ FLUS) is the most heterogeneous. Its use has to be limited to less than $7 \%$ (revised to $10 \%$ ) of the thyroid aspirates at any given center (1-3). 
Table 2 Pooled frequency, resection rate, ROM-resection and ROM-overall

\begin{tabular}{|c|c|c|c|}
\hline Parameters assessed & \multicolumn{3}{|c|}{ Pooled prevalence in \% $(95 \% \mathrm{Cl})$; I-squared } \\
\hline Frequency & 5.80 (4.24-7.35); 96.4\% & 8.68 (6.50-10.87); 98.6\% & 7.47 (6.12-8.81); 99.1\% \\
\hline Resection rate & 52.95 (38.56-67.35); 95.8\% & 26.49 (20.78-32.20); 93.8\% & 41.96 (35.70-48.21); 97.7\% \\
\hline ROM-resection & 39.12 (27.35-50.89); 79.0\% & 45.86 (32.15-59.56); 95.8\% & 26.29 (21.05-31.54); 93.2\% \\
\hline
\end{tabular}

ROM, risk of malignancy; $\mathrm{Cl}$, confidence interval.

Table $3 \mathrm{P}$ values comparing the pooled frequency, resection rate, ROM-resection, ROM-overall amongst India, Asia and the West

\begin{tabular}{lccc}
\hline & & \multicolumn{2}{c}{ ANOVA test, P value } \\
\cline { 2 - 4 } Parameters assessed & India vs. Asia & India vs. West & Asia vs. West \\
\hline Frequency & 0.75 & 1.00 & 1.00 \\
Resection rate & 0.12 & 0.47 & 0.89 \\
ROM-resection & 0.88 & 0.07 & 0.00 \\
ROM-overall & 1.00 & 0.21 & 0.84 \\
\hline
\end{tabular}

ROM, risk of malignancy.

An AUS/FLUS nodule on resection, may turn out to be non-neoplastic or neoplastic. TBSRTC 2007 recommends AUS/FLUS aspirates to be managed by repeat FNA and resection to be done only if the nodule is clinically or radiologically suspicious. The implied ROM of AUS/FLUS as per TBSRTC 2007 was $5-15 \%$ (1), which, in the recent edition of TBSRTC, has been revised to $10-30 \%$ if NIFTP is considered malignant and 6-18\%, on excluding NIFTP from the malignant group $(2,3)$. Due to the presence of data implicating geographic differences in thyroid practice (10$14)$, we performed this systematic meta-analysis to assess differences, if any, between the frequency, RR and ROM of AUS/FLUS across India, rest of Asia and the West.

Marked heterogeneity was found across the studies from all the zones for all the parameters assessed (I-squared ranged from $70.3 \%$ to $99.1 \%$ ), as was also noted in previously published meta-analyses (6-9). This stems partly from the non-specific diagnostic criteria of AUS/FLUS. Focal/extensive but mild cytological and/or architectural atypia not enough to be classified into a higher category; atypia in follicular/lymphoid or other cells, all are grouped under AUS/FLUS (1). Hence, most of the neoplastic and non-neoplastic thyroid pathologies can show AUS/ FLUS cytology, though high-grade malignancies are less represented in this category (77-80). There may also be regional and individual differences in the interpretation of the Bethesda criteria. A more robust application of TBSRTC and the practice of taking consensus before reporting, may help reduce this heterogeneity.

The overall pooled estimate of frequency of AUS/FLUS was $7.3 \%$ in our analysis. Against the recommended 7\% cut-off (1), pooled estimates of frequency were marginally high in the West (7.5\%) and Asia (8.7\%), but low in India (5.8\%).

Despite similar frequencies, the pooled estimates of $\mathrm{RR}$ and ROM-resection were quite different across the three geographical regions. Asia recorded the lowest RR (26.5\%), suggesting that Asian clinicians took a more selective surgical approach; to avoid overtreatment, a conservative management of active follow-up is preferred for low-risk thyroid carcinomas (12), most of which show indeterminate cytology (TBSRTC categories III/IV/ V). India had the highest pooled RR (53\%). The reason why these patients were operated upon: whether repeat aspirate showed a higher Bethesda category, patient's choice or due to institutional preference, is not clear. Being a developing nation, there is always a concern regarding patients being lost to follow-up, especially those from the lower socio-economic group. The western studies also showed a relatively high pooled RR (42\%). Hence, patients 

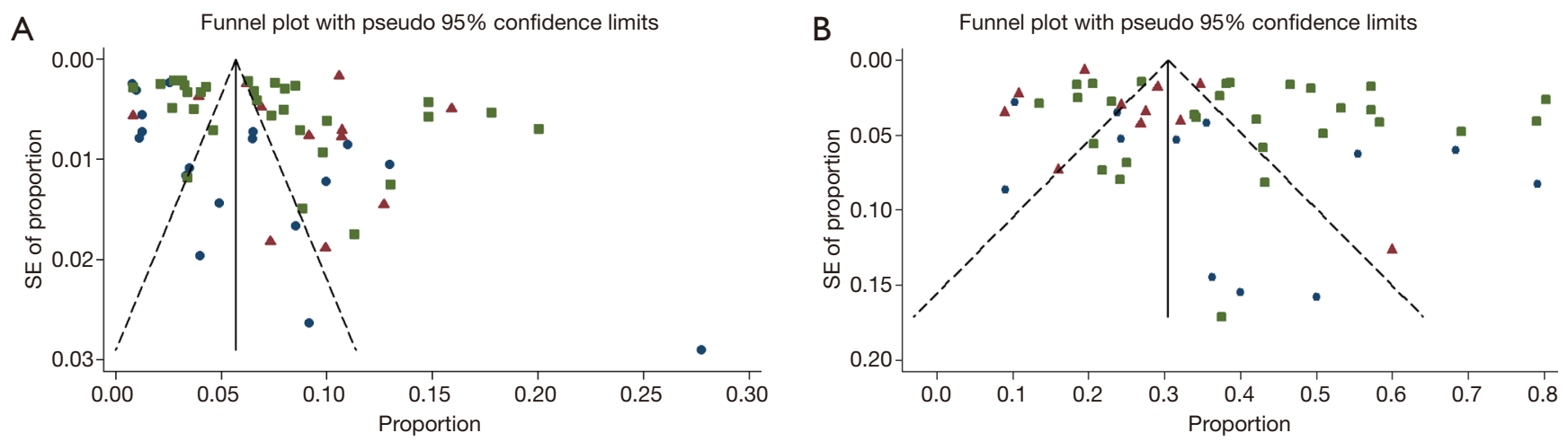

\begin{tabular}{|ccc|}
\hline $\begin{array}{c}\text { India } \\
\text { West }\end{array}$ & ----- Lower $\mathrm{Cl}$ \\
----- Upper $\mathrm{Cl}$ & & - Pooled \\
\hline
\end{tabular}
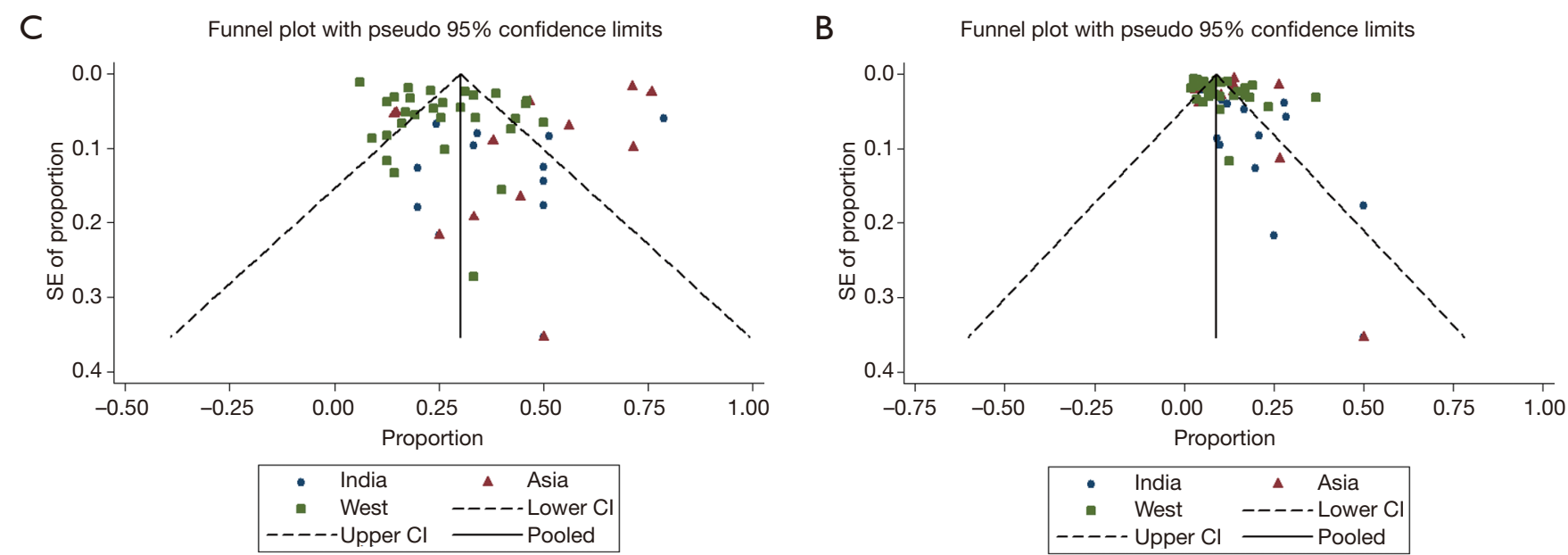

Figure 4 Funnel plots prepared for the studies included in the meta-analysis to evaluate: (A) frequency. Egger's regression test confirmed presence of publication bias in Indian $(\mathrm{P}=0.00)$ and Western studies $(\mathrm{P}=0.01)$, but none in Asian studies $(\mathrm{P}=0.77)$. (B) Resection rate. Egger's regression test showed absence of publication bias in Indian $(\mathrm{P}=0.08)$, Asian $(\mathrm{P}=0.38)$ and Western studies $(\mathrm{P}=0.35)$. (C) Risk of malignancyresection. Egger's regression test confirmed presence of publication bias only in Western studies $(\mathrm{P}=0.01)$, but none in Indian $(\mathrm{P}=0.26)$ and Asian $(\mathrm{P}=0.07)$ studies. (D) Risk of malignancy-overall. Egger's regression test confirmed presence of publication bias in Indian $(\mathrm{P}=0.03)$ and Western $(\mathrm{P}=0.01)$ studies, but none in Asian $(\mathrm{P}=0.52)$ studies.

in the West and India are more likely to be operated upon following a diagnosis of AUS than in the rest of Asia.

While the implied ROM for AUS/FLUS, as per TBSRTC 2007 is $5-15 \%$ (1), the pooled ROM-resection, considering all the included studies, was $33.3 \%$. ROMresection of the three zones when evaluated separately, ranged from $26-46 \%$. Although the implied ROM has been enhanced to $10-30 \%$ in the revised TBSRTC $(2,3)$, the values derived from Asian and Indian studies remained higher than others. A low RR is one of the causes for a high ROM-resection (46\%) in the Asian population where stricter clinical and radiological criteria are followed for surgery. The opposite holds for the Western studies, and the pooled estimates of ROM of the Asian and western studies were statistically different. The pooled estimate of ROM-resection in the Indian studies was intermediate between that of Asia and West despite the highest RR. This discrepancy is difficult to explain. One of the reasons could be variability in making a decision in borderline cases with doubtful PTC-type nuclear features. A low threshold for nuclear features will lead to a cytological diagnosis of "suspicious for PTC", decreasing the ROM of AUS/ FLUS (12). This especially holds true for the follicular variant of PTC (FVPTC) and its borderline counterpart 
NIFTP, which show subtle nuclear features, and are more susceptible to observer variation $(10,81-83)$. It has been documented that AUS/FLUS diagnosis recognizes low-risk PTC, mostly FVPTC and low-stage PTC in contrast to a malignant FNA diagnosis which is associated with highrisk PTC (77-80). A decrease in ROM has also been seen in the West but not so much in Asia, when cases of NIFTP are removed from malignancy $(12,13)$, thereby suggesting that besides the lower RR of indeterminate nodules, the diagnostic threshold of PTC-type nuclear features is higher in Asia than in the West (12). Bychkov et al., in their study based on data derived from six tertiary thyroid cancer centers representing five Asian countries, documented a 6\% absolute decrease in ROM of AUS/FLUS after excluding NIFTP (13), in contrast to $11 \%$ (95\% CI: 4-19\%) reported in a meta-analysis based on four datasets from the western population (84). In the current study, low-grade cancers were the least common (24.4\%) in the Asian cohort, followed by Indian (41.7\%), and Western (51.8\%). This also suggests that the threshold of Indian pathologists for nuclear features is intermediate between Asian and Western pathologists. Studies comparing inter-observer variation among India, Asian and Western pathologists may help in confirming or refuting this possibility. Hirokawa in 2002 documented lack of inter-observer reproducibility between Japanese and American pathologists in interpretation of encapsulated follicular thyroid lesions on histology. The latter were more likely to diagnose them as FVPTC than the former (10). A recent study found inter and intraobserver variation in interpretation of nuclear features of NIFTP among nine Asian pathologists (82), in contrast to excellent inter-observer agreement seen in another study in which pathologists from California, Japan and UK participated (85).

To accommodate for the high ROM reported by various studies, TBSRTC 2017 recommended sub-classification of AUS/FLUS depending upon the nature (nuclear and/ or architectural) of atypia present and the type of cells involved (follicular, Hurthle, lymphoid) along with detailed description of the case to improve pathologist-clinician communication and understanding; but the recommended management plan remains uniform across the subtypes, and includes the option of molecular testing or lobectomy besides repeat FNA $(2,3)$. Sub-classification can help in predicting the type of likely neoplasia, which in turn can help in deciding further management (80). As we analyzed studies which had used TBSRTC 2007, the cases had not been sub-classified. Availability of molecular facilities and adequate follow-up services also impact the RR and ROM across countries as well as individual centers.

Another important factor influencing ROM is disease prevalence, which varies not only from country to country but also within different geographical areas of a country (74-76) as well as from institute to institute depending upon the level of hospital care provided. A tertiary care hospital or a cancer center is bound to have higher ROM than regional hospitals. It has also been shown that higher the ROM of all operated nodules, higher will be the ROM of each category (12). Lastly, publication bias will also affect statistics.

While the ROM-resection confers with malignancy rate among all resected nodules, the ROM-overall, which ranged from $10-14 \%$, conveys the proportion of malignancies to total AUS aspirates. As only a proportion of the AUS/FLUS nodules get resected, the actual ROM will be somewhere between the two values. Interestingly, pooled proportions of ROM-overall were similar across the three regions (Table 2), suggesting that AUS is still a relatively homogeneous category under TBSRTC.

There are some limitations of our study. Besides the publication bias, we envisage a selection bias also as our data analysis is retrospective. Also, we had to exclude many studies where it was not possible to calculate frequency, RR or ROM of AUS/FLUS, or studies in which pre-operative radiology or molecular analyses were used which could have biased the RR and the ROM. Another limitation was the substantial heterogeneity among the included studies.

\section{Conclusions}

Our meta-analysis provides an updated assessment of the thyroid cytology practice in India with reference to the most heterogeneous Bethesda category of AUS/FLUS, and its comparison with the rest of Asia and the west. All the studies showed marked heterogeneity. While the pooled prevalence of AUS/FLUS was similar across the Indian, Asian and Western cohorts, and neared the recommended upper limit of $7 \%$, the pooled RR and ROM-resection varied across the three geographical zones. The RR of AUS/FLUS in India was the highest, probably reflecting the clinician's apprehension of patients being lost to followup. RR was the lowest in the rest of Asia owing to their policy of active surveillance in indeterminate aspirates with otherwise benign clinical findings. ROM of AUS/FLUS in all the three regions was higher than the recommended range; being lowest for West followed by India and highest 
for Asia, due to varying RRs, observer variations and cancer prevalence. All these factors lead to marked regional differences in thyroid clinical practice, much different from the prescribed international guidelines.

\section{Acknowledgments}

We thank Dr. Kennichi Kakudo for his invaluable inputs and guidance during the conduct of the study (Kennichi Kakudo, MD, PhD. Department of Pathology and Thyroid Disease Center, Izumi City General Hospital, Izumi City, Osaka 594-0073, Japan); we thank Dr. Huy Gia Vuong for guiding us in collection and analysis of data (Huy Gia Vuong, MD, PhD. Department of Pathology, Oklahoma University Health Sciences Center, Oklahoma City, OK 73104, USA); we thank Dr. Andrey Bychkov for his inputs during data collection and evaluation (Andrey Bychkov, MD, PhD. Department of Pathology, Kameda Medical Center, Kamogawa City, Chiba 296-8602, Japan).

Funding: None.

\section{Footnote}

Provenance and Peer Review: This article was commissioned by the Guest Editor (Kennichi Kakudo) for the series "Asian and Western Practice in Thyroid Pathology: Similarities and Differences" published in Gland Surgery. The article was sent for external peer review organized by the Guest Editor and the editorial office.

Reporting Checklist: The authors have completed the PRISMA reporting checklist. Available at http://dx.doi. org/10.21037/gs-20-392

Conflicts of Interest: All authors have completed the ICMJE uniform disclosure form (available at http:// dx.doi.org/10.21037/gs-20-392). The series "Asian and Western Practice in Thyroid Pathology: Similarities and Differences" was commissioned by the editorial office without any funding or sponsorship. The authors have no other conflicts of interest to declare.

Ethical Statement: The authors are accountable for all aspects of the work in ensuring that questions related to the accuracy or integrity of any part of the work are appropriately investigated and resolved.
Open Access Statement: This is an Open Access article distributed in accordance with the Creative Commons Attribution-NonCommercial-NoDerivs 4.0 International License (CC BY-NC-ND 4.0), which permits the noncommercial replication and distribution of the article with the strict proviso that no changes or edits are made and the original work is properly cited (including links to both the formal publication through the relevant DOI and the license). See: https://creativecommons.org/licenses/by-nc-nd/4.0/.

\section{References}

1. Cibas ES, Ali SZ. The Bethesda System for Reporting Thyroid Cytopathology. Thyroid 2009;19:1159-65.

2. Cibas ES, Ali SZ. The 2017 Bethesda System for Reporting Thyroid Cytopathology. J Am Soc Cytopathol 2017;6:217-22.

3. Krane JF, Nayar R, Renshaw AA. Atypia of Undetermined Significance/ Follicular Lesion of Undetermined Significance. In: Ali SZ, Cibas ES. The Bethesda system for reporting thyroid cytopathology: definitions, criteria, and explanatory notes $2 \mathrm{nd}$ ed. Switzerland: Springer Nature, 2018:49-70.

4. Haugen BR, Alexander EK, Bible KC, et al. 2015 American Thyroid Association Management Guidelines for Adult Patients with Thyroid Nodules and Differentiated Thyroid Cancer: The American Thyroid Association Guidelines Task Force on Thyroid Nodules and Differentiated Thyroid Cancer. Thyroid 2016;26:1-133.

5. Bongiovanni M, Spitale A, Faquin WC, et al. The Bethesda System for Reporting Thyroid Cytopathology: a meta-analysis. Acta Cytol 2012;56:333-9.

6. Sheffield BS, Masoudi H, Walker B, et al. Preoperative diagnosis of thyroid nodules using the Bethesda System for Reporting Thyroid Cytopathology: a comprehensive review and meta-analysis. Expert Rev Endocrinol Metab 2014;9:97-110.

7. Straccia P, Rossi ED, Bizzarro T, et al. A metaanalytic review of the Bethesda System for Reporting Thyroid Cytopathology: Has the rate of malignancy in indeterminate lesions been underestimated? Cancer Cytopathol 2015;123:713-22.

8. Krauss EA, Mahon M, Fede JM, et al. Application of the Bethesda Classification for Thyroid Fine-Needle Aspiration: Institutional Experience and Meta-analysis. Arch Pathol Lab Med 2016;140:1121-31. 
9. Ahn SH, Kim SD, Jeong WJ. Comparison of risk of malignancy in a subgroup with atypia of undetermined significance/follicular lesion of undetermined significance: A meta-analysis. Head Neck 2017;39:1699-710.

10. Hirokawa M, Carney JA, Goellner JR, et al. Observer variation of encapsulated follicular lesions of the thyroid gland. Am J Surg Pathol 2002;26:1508-14.

11. Bychkov A, Hirokawa M, Jung CK, et al. Low Rate of Noninvasive Follicular Thyroid Neoplasm with PapillaryLike Nuclear Features in Asian Practice. Thyroid 2017;27:983-4.

12. Kakudo K, Higuchi M, Hirokawa M, et al. Thyroid FNA cytology in Asian practice-Active surveillance for indeterminate thyroid nodules reduces overtreatment of thyroid carcinomas. Cytopathology 2017;28:455-66.

13. Bychkov A, Keelawat S, Agarwal S, et al. Impact of noninvasive follicular thyroid neoplasm with papillary-like nuclear features on the Bethesda system for reporting thyroid cytopathology: a multi-institutional study in five Asian countries. Pathology 2018;50:411-7.

14. Vuong HG, Tran TTK, Bychkov A, et al. Clinical impact of non-invasive follicular thyroid neoplasm with papillarylike nuclear features on the risk of malignancy in the Bethesda system for reporting thyroid cytopathology: a meta-analysis of 14,153 resected thyroid nodules. Endocr Pract 2019;25:491-502.

15. Agarwal S, Jain D. Thyroid Cytology in India: Contemporary Review and Meta-analysis. J Pathol Transl Med 2017;51:533-47.

16. Moher D, Liberati A, Tetzlaff J, et al. Preferred reporting items for systematic reviews and meta-analyses: the PRISMA statement. PLoS Med 2009;6:e1000097.

17. Arul P, Akshatha C, Masilamani S. A study of malignancy rates in different diagnostic categories of the Bethesda system for reporting thyroid cytopathology: An institutional experience. Biomed J 2015;38:517-22.

18. Badge SA, Ovhal AG, Azad K, et al. Study of fine-needle aspiration cytology of thyroid lesions in rural area of Bastar district, Chhattisgarh. Int J Health Sci Res 2016;6:73-9.

19. Bhartiya R, Mallik M, Kumari N, et al. Evaluation of thyroid lesions by fine-needle aspiration cytology based on Bethesda System for Reporting Thyroid Cytopathology classification among the population of South Bihar. Indian J Med Paediatr Oncol 2016;37:265-70.

20. Chandra S, Chandra H, Bisht SS. Malignancy rate in thyroid nodules categorized as atypia of undetermined significance or follicular lesion of undetermined significance: an institutional experience. J Cytol
2017;34:144-8.

21. Garg S, Desai NJ, Mehta D, et al. To establish Bethesda system for diagnosis of thyroid nodules on the basis of FNAC with histopathological correlation. J Clin Diagn Res 2015;9:EC17-21.

22. Garg S, Naik LP, Kothari KS, et al. Evaluation of thyroid nodules classified as Bethesda category III on FNAC. J Cytol 2017;34:5-9.

23. Kannan S, Raju N, Kekatpure V, et al. Improving Bethesda Reporting in Thyroid Cytology: A Team Effort Goes a Long Way and Still Miles to Go.... Indian J Endocrinol Metab 2017;21:277-81.

24. Khatib Y, Mulla A, Patel RD, et al. Classification of thyroid FNA smears into Bethesda categories and their correlation with thyroid function tests. Sch J Appl Med Sci 2016;4:916-23.

25. Mahajan S, Srinivasan R, Rajwanshi A, et al. Risk of Malignancy and Risk of Neoplasia in the Bethesda Indeterminate Categories: Study on 4,532 Thyroid FineNeedle Aspirations from a Single Institution in India. Acta Cytol 2017;61:103-10.

26. Maity P, Jha AK, Sengupta M, et al. Thyroid bethesda atypia of undetermined significance or follicular lesion of undetermined significance (AUS/FLUS): A heterogenous group. J Cytol 2019;36:200-4.

27. Mamatha M, Sekhar SC, Rani HS, et al. A comparative study between conventional system and the Bethesda system applied for reporting thyroid cytopathology. Int Arch Integr Med 2015;2:87-95.

28. Mehra P, Verma AK. Thyroid cytopathology reporting by the Bethesda system: a two-year prospective study in an academic institution. Patholog Res Int 2015;2015:240505.

29. Mondal SK, Sinha S, Basak B, et al. The Bethesda system for reporting thyroid fine needle aspirates: a cytologic study with histologic follow-up. J Cytol 2013;30:94-9.

30. Prathima S, Suresh TN, Harendra Kumar ML, et al. Impact of the Bethesda system in reporting thyroid cytopathology. Thyroid Res Pract 2016;13:9-14.

31. Roy S, Prabhu AJ, Abraham DT, et al. An insight into the utility of sub-categorisation of atypia of undetermined significance for risk stratification: A retrospective study on an Indian cohort with histopathological correlation. Acta Cytol 2019;63:182-8.

32. Shankar SP, Meenakshisundaram K, Rajalakshmi V, et al. The Bethesda System for reporting thyroid cytopathology: A two year retrospective review in a tertiary care hospital. Indian J Pathol Oncol 2016;3:48-54.

33. Solanki R, Chaudhary VK, Sharma M, et al. Validity 
assessment of 'the Bethesda System for Reporting Thyroid Cytopathology'. Int J Health Sci Res 2016;6:126-32.

34. Alabdulqader NA, Shareef SQ, Ali JA, et al. Application of the Bethesda System for Reporting Thyroid Cytopathology in the Eastern Province of Saudi Arabia: A Follow-Up Study. Acta Cytol 2015;59:233-8.

35. Al-Abbadi MA, Shareef SQ, Ali JA, et al. Application of the Bethesda System for Reporting Thyroid Cytopathology in the Eastern Province of Saudi Arabia: phase I pilot retrospective analysis. Acta Cytol 2013;57:481-8.

36. Al Dawish MA, Robert AA, Muna A, et al. Bethesda System for Reporting Thyroid Cytopathology: A threeyear study at a tertiary care referral center in Saudi Arabia. World J Clin Oncol 2017;8:151-7.

37. Kim M, Park HJ, Min HS, et al. The Use of the Bethesda System for Reporting Thyroid Cytopathology in Korea: A Nationwide Multicenter Survey by the Korean Society of Endocrine Pathologists. J Pathol Transl Med 2017;51:410-7.

38. Kim M, Kim JE, Kim HJ, et al. Cytologic Diagnosis of Noninvasive Follicular Thyroid Neoplasm with Papillarylike Nuclear Features and Its Impact on the Risk of Malignancy in the Bethesda System for Reporting Thyroid Cytopathology: An Institutional Experience. J Pathol Transl Med 2018;52:171-8.

39. Lee YB, Cho YY, Jang JY, et al. Current status and diagnostic values of the Bethesda system for reporting thyroid cytopathology in a papillary thyroid carcinomaprevalent area. Head Neck 2017;39:269-74.

40. Limlunjakorn P, Keelawat S, Bychkov A. Evaluation of thyroid fine needle aspiration cytology by the Bethesda reporting system: a retrospective analysis of rates and outcomes from the King Chulalongkorn Memorial Hospital. J Med Assoc Thai 2017;100:783.

41. Liu Z, Liu D, Ma B, et al. History and Practice of Thyroid Fine-Needle Aspiration in China, Based on Retrospective Study of the Practice in Shandong University Qilu Hospital. J Pathol Transl Med 2017;51:528-32.

42. Mufti ST, Molah R. The Bethesda System for Reporting Thyroid Cytopathology : A Five-Year Retrospective Review of One Center Experience. Int J Health Sci (Qassim) 2012;6:159-73.

43. Naz S, Hashmi AA, Khurshid A, et al. Diagnostic accuracy of Bethesda system for reporting thyroid cytopathology: an institutional perspective. Int Arch Med 2014;7:46.

44. Satoh S, Yamashita H, Kakudo K. Thyroid Cytology: The Japanese System and Experience at Yamashita Thyroid Hospital. J Pathol Transl Med 2017;51:548-54.
45. Bernstein JM, Shah M, MacMillan C, et al. Institutionspecific risk of papillary thyroid carcinoma in atypia/ follicular lesion of undetermined significance. Head Neck 2016;38 Suppl 1:E1210-5.

46. Bohacek L, Milas M, Mitchell J, et al. Diagnostic accuracy of surgeon-performed ultrasound-guided fineneedle aspiration of thyroid nodules. Ann Surg Oncol 2012;19:45-51.

47. Bongiovanni M, Crippa S, Baloch Z, et al. Comparison of 5-tiered and 6-tiered diagnostic systems for the reporting of thyroid cytopathology. Cancer Cytopathol 2012;120:117-25.

48. Bonzanini M, Amadori P, Morelli L, et al. Subclassification of the "grey zone" of thyroid cytology; a retrospective descriptive study with clinical, cytological, and histological correlation. J Thyroid Res 2011;2011:251680.

49. Brandler TC, Aziz MS, Coutsouvelis C, et al. Young investigator challenge: Atypia of undetermined significance in thyroid FNA: Standardized terminology without standardized management - a closer look at repeat FNA and quality measures. Cancer Cytopathol 2016;124:37-43.

50. Can N, Aytürk S, Taştekin E, et al. Malignancy Rates in Bethesda Category AUS/FLUS: Single Center Experience. Acta Oncol Turc 2016;49:158-63.

51. Cristo AP, Goldstein HF, Faccin CS, et al. Increasing diagnostic effectiveness of thyroid nodule evaluation by implementation of cell block preparation in routine USFNA analysis. Arch Endocrinol Metab 2016;60:367-73.

52. Deniwar A, Hambleton C, Thethi T, et al. Examining the Bethesda criteria risk stratification of thyroid nodules. Pathol Res Pract 2015;211:345-8.

53. Faquin WC, Wong LQ, Afrogheh AH, et al. Impact of reclassifying noninvasive follicular variant of papillary thyroid carcinoma on the risk of malignancy in the Bethesda System for Reporting Thyroid Cytopathology. Cancer Cytopathol 2016;124:181-7.

54. Güney $\mathrm{G}$, Şahiner İT. Malignancy rates of thyroid cytology: Cyst fluid benign or non-diagnostic? Med Sci Monit 2017;23:3556-61.

55. Guo A, Kaminoh Y, Forward T, et al. Fine Needle Aspiration of Thyroid Nodules Using the Bethesda System for Reporting Thyroid Cytopathology: An Institutional Experience in a Rural Setting. Int J Endocrinol 2017;2017:9601735.

56. Harvey AM, Mody DR, Amrikachi M. Thyroid fine-needle aspiration reporting rates and outcomes before and after Bethesda implementation within a combined academic and community hospital system. Arch Pathol Lab Med 
2013;137:1664-8.

57. Ho AS, Sarti EE, Jain KS, et al. Malignancy rate in thyroid nodules classified as bethesda category III (AUS/FLUS). Thyroid 2014;24:832-9.

58. Horne MJ, Chhieng DC, Theoharis C, et al. Thyroid follicular lesion of undetermined significance: Evaluation of the risk of malignancy using the two-tier subclassification. Diagn Cytopathol 2012;40:410-5.

59. Jo VY, Stelow EB, Dustin SM, et al. Malignancy risk for fine-needle aspiration of thyroid lesions according to the Bethesda system for reporting thyroid cytopathology. Am J Clin Pathol 2010;134:450-6.

60. Kantola S, Virani N, Haus C, et al. Prospective evaluation of impact of using the Bethesda System for Reporting Thyroid Cytopathology: an institutional experience. J Am Soc Cytopathol 2015;4:25-9.

61. Lobo C, McQueen A, Beale T, et al. The UK Royal College of pathologists thyroid fine-needle aspiration diagnostic classification is a robust tool for the clinical management of abnormal thyroid nodules. Acta Cytol 2011;55:499-506.

62. Luu MH, Fischer AH, Stockl TJ, et al. Atypical follicular cells with equivocal features of papillary thyroid carcinoma is not a low-risk cytologic diagnosis. Acta Cytol 2011;55:526-30.

63. Muratli A, Erdogan N, Sevim S, et al. Diagnostic efficacy and importance of fine-needle aspiration cytology of thyroid nodules. J Cytol 2014;31:73-8.

64. Nayar R, Ivanovic M. The indeterminate thyroid fineneedle aspiration: experience from an academic center using terminology similar to that proposed in the 2007 National Cancer Institute Thyroid Fine Needle Aspiration State of the Science Conference. Cancer 2009;117:195-202.

65. Olson MT, Boonyaarunnate T, Aragon Han P, et al. A tertiary center's experience with second review of 3885 thyroid cytopathology specimens. J Clin Endocrinol Metab 2013;98:1450-7.

66. Paajanen I, Metso S, Jaatinen P, et al. Thyroid FNA diagnostics in a real-life setting: Experiences of the implementation of the Bethesda system in Finland. Cytopathology 2018;29:189-95.

67. Renshaw AA, Gould EW. Adequate sampling of multiple thyroid nodules by fine-needle aspiration. Cancer Cytopathol 2017;125:848-53.

68. Tepeoğlu M, Bilezikçi B, Bayraktar SG. A histological assessment of the Bethesda system for reporting thyroid cytopathology (2010) abnormal categories: A series of 219 consecutive cases. Cytopathology 2014;25:39-44.
69. Ugurluoglu C, Dobur F, Karabagli P, et al. Fine needle aspiration biopsy of thyroid nodules: cytologic and histopathologic correlation of 1096 patients. Int J Clin Exp Pathol 2015;8:14800-5.

70. Wu HH, Inman A, Cramer HM. Subclassification of "atypia of undetermined significance" in thyroid fineneedle aspirates. Diagn Cytopathol 2014;42:23-9.

71. Yang J, Schnadig V, Logrono R, et al. Fine-needle aspiration of thyroid nodules: a study of 4703 patients with histologic and clinical correlations. Cancer 2007;111:306-15.

72. Yassa L, Cibas ES, Benson CB, et al. Long-term assessment of a multidisciplinary approach to thyroid nodule diagnostic evaluation. Cancer 2007;111:508-16.

73. Zhou H, Baloch ZW, Nayar R, et al. Noninvasive follicular thyroid neoplasm with papillary-like nuclear features (NIFTP): Implications for the risk of malignancy (ROM) in the Bethesda System for Reporting Thyroid Cytopathology (TBSRTC). Cancer Cytopathol 2018;126:20-6.

74. Bray F, Ferlay J, Soerjomataram I, et al. Global cancer statistics 2018: GLOBOCAN estimates of incidence and mortality worldwide for 36 cancers in 185 countries. CA Cancer J Clin 2018;68:394-424.

75. Comparison of cancer incidence and patterns of all population based cancer registries. In: National Centre for Disease Informatics and Research. National Cancer Registry Programme Indian Council of Medical Research. Three-year report of population based cancer registries 2012-2014. Bengaluru: NCDIR-NCRP, 2016:45,60.

76. Smith RD, Mallath MK. History of the Growing Burden of Cancer in India: From Antiquity to the 21st Century. J Glob Oncol 2019;5:1-15.

77. VanderLaan PA, Marqusee E, Krane JF. Features associated with locoregional spread of papillary carcinoma correlate with diagnostic category in the Bethesda system for reporting thyroid cytopathology. Cancer Cytopathol 2012;120:245-53.

78. Liu X, Medici M, Kwong N, et al. Bethesda categorization of thyroid nodule cytology and prediction of thyroid cancer type and prognosis. Thyroid 2016;26:256-61.

79. Evranos B, Polat SB, Baser H, et al. Bethesda classification is a valuable guide for fine needle aspiration reports and highly predictive especially for diagnosing aggressive variants of papillary thyroid carcinoma. Cytopathology 2017;28:259-67.

80. Guleria P, Agarwal S, Iyer VK, et al. Subcategorisation of AUS/FLUS thyroid lesions as per the 2017 Bethesda System for Reporting Thyroid Cytopathology: a 
retrospective study from a tertiary care centre analysing risk of malignancy (ROM) of the different subcategories. J Clin Pathol 2019;72:771-7.

81. Lloyd RV, Erickson LA, Casey MB, et al. Observer variation in the diagnosis of follicular variant of papillary thyroid carcinoma. Am J Surg Pathol 2004;28:1336-40.

82. Liu Z, Bychkov A, Jung CK, et al. Interobserver and intraobserver variation in the morphological evaluation of noninvasive follicular thyroid neoplasm with papillarylike nuclear features in Asian practice. Pathol Int 2019;69:202-10.

83. Mahajan S, Agarwal S, Kocheri N, et al. Cytopathology of non-invasive follicular thyroid neoplasm with papillary-like nuclear features: A comparative study with

Cite this article as: Guleria P, Mani K, Agarwal S. Indian experience of AUS/FLUS diagnosis: is it different from rest of Asia and the West?-A systematic review and meta-analysis. Gland Surg 2020;9(5):1797-1812. doi: 10.21037/gs-20-392 similar patterned papillary thyroid carcinoma variants. Cytopathology 2018;29:233-40.

84. Layfield LJ, Baloch ZW, Esebua M, et al. Impact of the Reclassification of the Non-Invasive Follicular Variant of Papillary Carcinoma as Benign on the Malignancy Risk of the Bethesda System for Reporting Thyroid Cytopathology: A Meta-Analysis Study. Acta Cytol 2017;61:187-93.

85. Thompson LDR, Poller DN, Kakudo K, et al. An International Interobserver Variability Reporting of the Nuclear Scoring Criteria to Diagnose Noninvasive Follicular Thyroid Neoplasm with Papillary-Like Nuclear Features: a Validation Study. Endocr Pathol 2018;29:242-9. 